\title{
Searching for pale, getting rickets
}

\author{
Said Bamashmus $\cdot$ Mohamed Bamosmoosh • \\ Pietro Amedeo Modesti
}

Received: 25 January 2010/ Accepted: 23 February 2010/Published online: 23 March 2010

(C) SIMI 2010

\section{Case report}

\section{Said Bamashmus}

A 36-year-old woman presented with her 2-year child in the out-patient orthopaedic department of our hospital. She complained that her little boy was unable to walk properly without support. The child looked intelligent, aware of what was happening around him. However he was hypotonic with muscular weakness, cranial sutures were still widened and dental eruption was delayed. No other abnormal findings were found at the physical examination. Urine and essential blood tests were normal except for an increase in the serum alkaline phosphatase $(1,253 \mathrm{IU} / \mathrm{ml})$. The X-ray performed to his legs showed radiologic alteration at the epiphyseal growth plate due to decreased calcification of the hypertrophic zone and inadequate mineralization of the primary spongiosa. The orthopaedist asked to visit also the 15-year-old sister who was accompanying the little infant. The young woman had skeletal pain and most significantly a "rachitic rosary" due the prominence of the costochondral junctions.

These findings confirmed the suspect of the orthopaedist and he diagnosed in both patients the presents of rickets.

S. Bamashmus · M. Bamosmoosh

University of Science and Technology, Sanaa, Yemen

M. Bamosmoosh · P. A. Modesti ( $\square)$

Clinica Medica Generale e Cardiologia, Dept. Area Critica

Medico Chirurgica, University of Florence, Florence, Italy

e-mail: pamodesti@unifi.it

P. A. Modesti

Fondazione Don Carlo Gnocchi Onlus IRCCS Centro S.

Maria agli Ulivi, Pozzolatico, Italy
While speaking with the mother he found out that she wanted her children to be as much white as possible and did not let them get in contact with sunlight and obliged her daughter to dress the dark nighab since an early age. The physician advised the mother to give her children food rich with calcium and oral vitamin D, but explained and convinced her that sunlight is more important for the good health of her children than any other treatment. At the 6 months follow up, the little boy was fine and able to walk correctly and the clinical findings for his sister were improving.

\section{Comment}

\section{Mohamed Bamosmoosh, Pietro Amedeo Modesti}

A porcelain complexion has been coveted through the ages, but pale skin also comes with a host of challenges. The signs of rickets at physical examination are now rare in Western countries where the importance of the diet rich in calcium and vitamin D as well as of sunlight for a correct growth of infants and adolescents is well recognized. A low introduction of vitamin D and calcium is indeed mainly related to the socio-economic situation in developing countries (Nigeria, Ethiopia) [1-3]. A dark skin however requires a longer time exposure to the sun ultraviolet (UV) rays than a pale one and this is especially important for immigrants to countries characterized by few sunlight hours [4]. More recent reports are now indicating that also in countries, such as India, Pakistan, Iran and the Arabian Peninsula [5-7] rickets in adolescents, especially female, may be also associated to a reduced sunlight exposure of the children. In particular, in addition to indoor confinement for climatic conditions, two other two social habits 
contribute in reducing sunlight exposure of children. The first is the tribal, and in some cases the religious, habit to start covering with long garments (purdah) the body of girls during adolescence $[7,8]$, the period of the life where all strategies aimed at optimizing peak bone mass should be rather employed. The second conceptual model leading mothers not to let their children playing outdoors and not permit to sun rays to enter homes directly is the aesthetic search for a pale skin, socially considered a must of beauty [7, 9]. All these conditions are detectable in the present case report. This is not just a matter of developing country like Yemen, because the same search for a pale skin is also often felt by immigrants living in Europe possibly leading to low exposure to sunlight and rickets $[4,10]$.

A reduced exposure to sun light in urban areas of western countries is encountered not only in children forced to spend indoor almost $93 \%$ of time because of pollution and tall buildings, but also in patients treated with immunosuppressive therapy who search protection from sun exposure, and in the elderly living in nursing home residences. Pandemic obesity and aging also play a role because vitamin $\mathrm{D}$ is sequestrated by the fat, and 7-deidrocholesterol concentration decreases with aging [10].

It is now clear and incontrovertible that human milk is the best nutritive substance for infants during the first year. However, there is concern about its ability in providing children since the first few days of life with the daily requirement of vitamin D (400 IU according to the American Academy of Paediatrics) [4, 11]. Adequate intake of vitamin $\mathrm{D}$ cannot be met with human milk as its content is of $20-40 \mathrm{IU} / \mathrm{L}$ and is related to the lactating mother vitamin D status. Hypovitaminosis D was found in exclusively breast fed infants in United Arab Emirates $(82 \%)$ and Pakistan $(50 \%)$ and its peak incidence was in infants aged between 3 and 18 months [5]. Cow's milk has a higher content of vitamin D (400 IU/L) than human milk and the introduction, after the first world war, of the fortification of the milk with 100 IU vitamin D2 (ergocalciferol derived from the plants) per $8 \mathrm{oz}$, strongly contributed to the dramatic reduction of the incidence of rickets in USA and Europe. Vitamin D3 (cholecalciferol), which is synthesized by mammals and is also fish derived, has a greater efficacy in raising circulating 25-OH-D. Few foods contain naturally vitamin D (salmons, mackerel and cod liver oil, juice products, milk, yogurt, cheese) [11].

However the endogenous synthesis of vitamin D is more important than that of the dietary intake as $90 \%$ of the required vitamin $\mathrm{D}$ has to be produced in the skin through the action of the sun's ultraviolet (UV) rays that transform 7 dehydrocholesterol to previtamin D3 which through the heat of the skin becomes vitamin D3. Vitamin D is then transformed to the active metabolites 25-OH-D in the liver and then to $1,25(\mathrm{OH})_{2} \mathrm{D}$ in the kidney [12].
To avoid hypovitaminosis it is enough during summer months to have 10-15 min full body exposure during sun hours which are enough to produce 10.000-20.000 IU of vitamin D. Darker skin subjects require 5-10 min more because melatonin competes with the 7 dehydrocholesterol in absorbing the UV rays [4].

Sun exposure was the first cornerstone of social welfare in battling rickets. Rickets, however, can now return masked under other skin. As clinicians we have to empathise the public health campaigns advising the importance, specially for developing countries, to use of foods rich in calcium and vitamin $\mathrm{D}$, milk fortificated with vitamin $\mathrm{D}$, oral vitamin $\mathrm{D}$ intake and promoting outdoor activities [3, 4, 9-12].

These advices at the end are the same of older grandmas which used to say "drink up your milk and go playing outdoors".

\section{Conflict of interest None.}

\section{References}

1. Thacher TD, Fischer PR, Pettifor JM, Lawson JO, Isichei CO, Reading JC, Chan GM (1999) A comparison of calcium, vitamin $\mathrm{D}$, or both for nutritional rickets in Nigerian children. $\mathrm{N}$ Engl $\mathrm{J}$ Med 341:563-568

2. Muhe L, Lulseged S, Mason KE, Simoes EA (1997) Case-control study of the role of nutritional rickets in the risk of developing pneumonia in Ethiopian children. Lancet 349:1801-1804

3. Bishop N (1999) Rickets today-children still need milk and sunshine. N Engl J Med 341:602-604

4. Wagner CL, Greer FR (2008) American Academy of Pediatrics Section on Breastfeeding; American Academy of Pediatrics Committee on Nutrition. Prevention of rickets and vitamin D deficiency in infants, children, and adolescents. Pediatrics 122:1142-1152

5. Balasubramanian S, Ganesh R (2008) Vitamin D deficiency in exclusively breast fed infants. Indian J Med Res 127:250-255

6. Dahifar H, Faraji A, Yassobi S, Ghorbani A (2007) Asymptomatic rickets in adolescent girls. Indian J Pediatr 74:571-575

7. Bener A, Al-Ali M, Hoffmann GF (2009) High prevalence of vitamin D deficiency in young children in a highly sunny humid country: a global health problem. Minerva Pediatr 61:15-22

8. Dahifar H, Faraji A, Ghorbani A, Yassobi S (2006) Impact of dietary and lifestyle on vitamin D in healthy student girls aged 11-15 years. J Med Invest 53:204-208

9. Al-Atawi MS, Al-Alwan IA, Al-Mutair AN, Tamim HM, AlJurayyan NA (2009) Epidemiology of nutritional rickets in children. Saudi J Kidney Dis Transpl 20:260-265

10. Weisberg P, Scanlon KS, Li R, Cogswell ME (2004) Nutritional rickets among children in the United States: review of cases reported between 1986 and 2003. Am J Clin Nutr 80(6 Suppl):1697S-1705S

11. Holick MF, Chen TC (2008) Vitamin D deficiency: a worldwide problem with health consequences. Am J Clin Nutr 87:1080S$1086 \mathrm{~S}$

12. Reichrath $\mathbf{J}$ (2006) The challenge resulting from positive and negative effects of sunlight: how much solar UV exposure is appropriate to balance between risks of vitamin D deficiency and skin cancer? Prog Biophys Mol Biol 92:9-16 